\title{
Educação marcial: a contribuição da escola de artes marciais no processo formativo do jovem protagonista responsável
}

\author{
Fernando Duarte Martins de Oliveira
}

Resumo: Este trabalho apresenta um relato de experiência sobre a contribuição da escola de artes marciais como um ambiente capaz de formar cidadãos conscientes e cumpridores dos próprios deveres pessoais e sociais. Após uma breve análise sociológica sobre a condição existencial da juventude atual, faremos um aceno sobre a metodologia aplicada dentro da escola de arte marcial e como o processo pedagógico dessa metodologia atua na construção de um ambiente absolutamente propício ao desenvolvimento do jovem protagonista responsável. Após, relatamos dois casos particularmente interessantes, o primeiro sobre a formação protagonista de um jovem através da prática da arte marcial, e o seguinte sobre a recuperação da capacidade de construção de si mesmo, através de uma bela experiência de autodescoberta e auto realização por meio da responsabilização individual. Destacamos uma importante categoria teórico-empírica obtida com este estudo que evidenciará a positividade e a relevância dos resultados obtidos e relatados neste ensaio.

Palavras-chave: Pedagogia; Responsabilidade; Artes Marciais; Ontopsicologia.

Martial education: the martial arts school's contribution in the formative process of the responsible young leader

Abstract: This paper presents an experience report about the martial arts school contribution as an environment capable of forming conscious citizens and abiding to their own personal and social duties. After a brief sociological analysis of the existential condition of today's youth, we will make a nod on the methodology applied in the martial art school and how the learning process of this methodology works at building an absolutely conducive environment to the development of the young protagonist responsible. After, we report two particularly interesting cases, the first on the protagonist training of a young through the practice of martial art, and the following about the recovery of capacity of self-building, through a beautiful experience of self-discovery selfrealization through individual accountability. We highlight an important theoretical and empirical category obtained from this study which will show the positive and the relevance of the results obtained and reported in this work.

Keywords: Pedagogy; Responsibility; Martial Arts; Ontopsychology.

Educación marcial: la contribución de la escuela de artes marciales en el proceso formativo del joven protagonista responsable

Resumen: Este trabajo presenta un relato de experiencia sobre la contribución de la escuela de artes marciales como un ambiente capaz de formar ciudadanos conscientes y cumplidores de los propios deberes personales y sociales. Después de un breve análisis sociológico sobre la condición existencial de la juventud actual, haremos una exposición sobre la metodología aplicada dentro 
de la escuela de arte marcial y cómo el proceso pedagógico de esa metodología actúa en la construcción de un ambiente absolutamente propicio para el desarrollo del joven protagonista responsable. Después, relatamos dos casos particularmente interesantes, el primero sobre la formación protagonista de un joven a través de la práctica del arte marcial, y el siguiente sobre la recuperación de la capacidad de construcción de sí mismo, a través de una bella experiencia de autodescubrimiento y auto realización por medio de la responsabilidad individual. Destacamos una importante categoría teóricoempírica obtenida con este estudio que evidenciará la positividad y la relevancia de los resultados obtenidos y relatados en este ensayo.

Palabras clave: Educación; Responsabilidad; Artes marciales; Ontopsicología.

\section{Introdução}

As artes marciais são práticas cultivadas a mais de três mil anos como instrumentos de educação e conjunto de preceitos éticos, desenvolvendo lideranças, estimulando a autonomia e produzindo indivíduos responsáveis.

O potencial formativo do ensino das artes marciais reside na propriedade de empoderamento através do desenvolvimento físico, mental e emocional, fruto de um percurso que apresenta resultados corporais visíveis, e que exigem uma prática de repetição em busca da perfeição técnica.

Tal percurso se faz a partir da orientação de um preceptor, dentro de uma escola (seja escola em sentido físico ou abstrato), que exerce não só a autoridade legitimada pela demonstração do domínio e tirocínio ${ }^{1}$ da técnica, mas também a autoridade outorgada pela imagem, pelo exemplo e pelo próprio modo de perseguir a construção da grandiosidade de si mesmo através da arte marcial.

Sobre a construção com grandiosidade, Meneghetti afirma: "Cada coisa construída com grandiosidade tem o seu tempo, a sua seleção, o seu tirocínio de anos de trabalho e de preparação" (MENEGHETTI, 2010, p. 41). Entende-se, portanto, que, para qualquer realização grandiosa, é fundamental uma preparação intensa e um longo período de repetição, a tal ponto que o indivíduo se apropria daquele modo de fazer, daquela técnica,

\footnotetext{
${ }^{1}$ Tirocínio: “1 Primeiro ensino; aprendizado(...) 2 Prática, exercício preliminar indispensável ao desempenho de determinada profissão; experiência(...)3 Capacidade de discernimento(...)” (HOUAISS, 2009, p.1848). No sentido do texto, tirocínio se refere à capacidade de percepção e conhecimento da técnica, advinda da prática, que extrapola o aparato sensorial.
} 
percebendo e fazendo através de um conhecimento que extrapola os limites dos cinco sentidos.

A arte marcial funciona também como um modo de ser do indivíduo que busca construir a si mesmo, permitindo ao praticante, através da evolução da forma plástica da própria técnica, a construção de sua responsabilidade individual e social. Por consequência, acontece o desenvolvimento de um protagonismo motivado pelo ganho de autoconhecimento e autoconfiança, frutos do nascimento dessa responsabilidade.

O objetivo do presente trabalho é demonstrar, através de um relato de experiência, como o papel da escola de arte marcial é fundamental no processo de construção da perspectiva de responsabilidade, protagonismo e excelência que conduzirá o jovem aluno no percurso de aprimoramento gerador do tirocínio que transforma a técnica em arte e o praticante em protagonista.

\section{Escola de Artes Marciais: uma proposta de formação para o protagonismo}

Antes de falarmos sobre a necessidade de uma pedagogia capaz de formar jovens verdadeiramente protagonistas, não podemos nos furtar a fazer, nem que seja, uma breve análise sociológica sobre a condição existencial da juventude atual e sobre os riscos iminentes que essa condição representa para o futuro da humanidade.

\subsection{A Juventude Fora de Fase ${ }^{2}$}

A história contemporânea faz testemunho da hipoteca da cultura desde os anos cinquenta do século passado, com a consequência que afirma Meneghetti: "Desde que a cultura foi hipotecada pelos Estados Unidos, depois da Segunda Guerra Mundial, não ocorreram mais descobertas científicas a serviço do humano" (MENEGHETTI, 2014, p. 19). A partir da segunda metade do século $X X$, a humanidade viveu incontestáveis avanços tecnológicos; a Medicina, as Engenharias, a Química, os modos de produção, a indústria automobilística a comunicação e principalmente a informática computacional evoluíram de forma surpreendente. Porém, se observarmos cuidadosamente tais progressos, perceberemos que, apesar de impressionantes, em nada foram utilizados como função a

\footnotetext{
${ }^{2}$ A expressão "fora de fase" foi utilizada pelo Acad. Prof. Antonio Meneghetti em sua obra "Do Humanismo Histórico ao Humanismo Perene" (2014) para se referir a uma juventude envaidecida, que está sempre em movimento, mas nada realiza e não tem conexão com o próprio projeto de natureza.
} 
serviço do humano enquanto intencionalidade de realização ôntica ${ }^{3}$. Nos últimos cinquenta anos, a humanidade vem nutrindo, e simultaneamente sofrendo, um processo de cisão existencial em virtude do acolhimento de um determinado estereótipo. Sobre isso afirma Meneghetti:

\begin{abstract}
As nações mais avançadas do mundo, que afloram no vértice do consumismo de tecnocracia e de mercado, (...) apresentam no campo pedagógico grandes e graves problemas, que corrompem a possibilidade de terem futuros líderes, que contaminam a possibilidade dos jovens de serem protagonistas na história deste planeta (...) Isto é determinado por (...) um estereótipo que há pelo menos cinquenta anos, dirige uma psicologia de massa, de mercado, e uma cultura de universidade discutíveis como pesquisas e como resultados. Este tipo de psicologia surgiu por consequência bélica, não digo por causa dos Estados Unidos, mas por adaptação à sua exclusividade do imaginário fílmico.(...)

Este estereótipo, considerado como verdadeiro, unívoco, cobre as iniciativas, as novidades infinitas dos indivíduos e das nações, ocultando aquele instinto original à criatividade segundo as possibilidades históricas, segundo as vocações espirituais que cada povo no âmbito das constelações psíquicas possui (MENEGHETTI, 2007b, p. 199-200 apud CAROTENUTO, 2013, p. 415-416).
\end{abstract}

O estereótipo a que se refere o autor é uma cultura de informação memética ${ }^{4}$ e baseada na virtualidade computacional, na vida dentro da "web", sem a menor consciência ou contato com aquilo que é de fato real. No transcorrer das últimas seis décadas deu-se a ascensão de uma concepção gradualmente mais assistencialista tanto do ponto de vista biológico quanto sociológico e, partindo da pedagogia sistêmica (aquela aplicada e replicada pela família e pela escola) até as grandes políticas públicas, esse movimento vem desresponsabilizando o indivíduo através da aceitação e disseminação da ideia de que o mais fraco e menos capaz deve ser mais assistido e amparado, criando uma concepção de cultura que acaba por estimular a infantilização e a "desresponsabilização" dos jovens premiando a debilidade, tanto existencial quanto econômica. Dessa forma, a juventude desvirtua sua potencialidade para ser protagonista, desperdiçando a própria energia em consumismo esquizofrênico 5 . É como afirma Meneghetti:

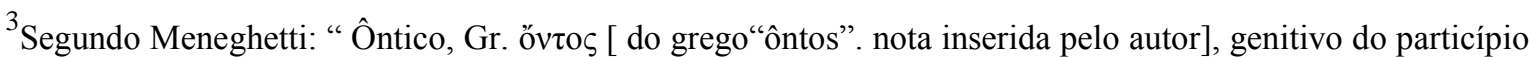
presente do verbo eỉuí $=$ ser. Participado pelo ser em si. O que constitui o princípio para qualquer possibilidade ou fato de existir. Atualidade da causa primeira de um processo. O princípio pelo qual é, ou não é." (MENEGHETTI, 2012, p. 188) .

4 “informação memética: é uma informação que não consente a reversibilidade de coincidência, com o real vida, não tem o retorno com o verdadeiro, o simples da natureza, é uma informação com fim em si mesma. É baseada sobre o estereótipo, monitor de deflexão,complexo, tradição etc." (MENEGHETTI,2012,p.164);

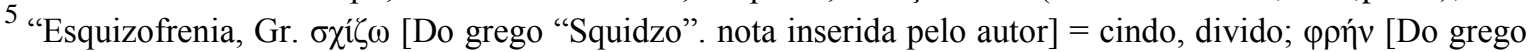
"frén". nota inserida pelo autor] = cérebro. Cérebro dividido. Estado da mente em que as funções ou partes operativas não efetuam a unidade de informação e de juízo. Distingue-se da neurose na medida em que é inconsciente. Em Ontopsicologia, distinguem-se duas formas de esquizofrenia: patológica e existencial. 1) A primeira é toda a fenomenologia segundo a verificação psiquiátrica e psicológica; 2) A segunda é própria da
} 
A ilimitada ignorância e insegurança que cada um sente dentro de si mesmo são dadas justamente pela falta de autoridade de existir na ordem de natureza: a maioria dos homens acredita em si mesmo porque há um sistema que os protege, existem as leis, as constituições etc., mas o autofundar-se em si mesmo é mais difícil (MENEGHETTI, 2015, p. 39).

Ao sistema convém estimular essa defasagem, uma vez que "a esquizofrenia coletiva impõe mercado" (MENEGHETTI, 2015, p. 31). Através dessa debilidade, constroem-se mercados baseados em discursos convencionais que se referem à memética: informações e conceitos vazios de significância e realidade, que se espalham rapidamente e se repetem obsessivamente; vende-se mais, ao preço de incitar a juventude a uma repetição de ciclo biológico ${ }^{6}$ e a cisão da própria ecceidade ${ }^{7}$ provocando uma espécie de esquizofrenia existencial que resulta por anular a identidade do indivíduo.

De uma perspectiva ontopsicológica ${ }^{8}$, a cisão do sujeito para com a realidade resulta por criar uma situação em que o indivíduo perde a potencialidade do protagonismo e abandona a própria capacidade de fazer economia de si mesmo, tornando-se incapaz de ser função enquanto agente social e, ao contrário, passa a exercer exclusivamente repetição do processo de anulação individual, fazendo cultura de massa.

\subsection{A Pedagogia que desenvolve o Protagonismo Responsável}

Apresentada a problemática, evidencia-se a necessidade de uma pedagogia que seja capaz de dar ao indivíduo a formação necessária para manter una a própria ecceidade e desenvolver o seu protagonismo dentro do contexto social em que opera e de acordo com a fase de maturidade que atravessa, pois é deste sujeito - uno e consciente do próprio ser - que depende o futuro das sociedades. Nesse sentido afirma Meneghetti:

consciência aporética da cultura humana: a mente não sabe o que é, o porquê do próprio ser, de onde vem e para onde vai. A mente se encontra dividida da razão do ser por causa da interferência do monitor de deflexão prevalecente"(MENEGHETTI,2012,p.98). No sentido do texto, consumismo esquizofrênico se refere a um hábito de consumir sem necessidade real, se dá pela falta de contato do indivíduo com a própria verdade, ele não conhece o real de si mesmo, padece de esquizofrenia existencial.

6 “O ciclo biológico - ou biogênese - é um prefixado que a própria vida garante com a finalidade de acrescer a espécie. [...] É uma dimensão que determina um ser humano a nascer, atingir a maturidade fisiológica, procriar e morrer após ter concluído o dever familístico [...]” (MENEGHETTI, 2012, p. 46).

7 "hecceidade s.f. FIL no pensamento de Duns Scotus (c1265 -1308), o caráter particular, individual,único de um ente, que o distingue de todos os outros;[...]" (HOUAISS, 2009, p.1007-1008).

8 "A Ontopsicologia é a mais recente entre as ciências contemporâneas que tem por objeto a análise da atividade psíquica [...] Significa estudo dos comportamentos psíquicos em primeira atualidade, não excluída a compreensão do ser; estudar psicologia segundo coordenadas do real, ou intencionalidade da ação-vida, ou ação-ser. Trata-se de partir do real fato antropológico e não da sua cultura ou de suas reflexões" (MENEGHETTI, 2010, p. 19). 
[...] o povo é o núcleo, o centro do poder, porém "povo" não é entendido em sentido naturista, primitivo - o índio, o aborígene etc. -, mas sim o homem de Sócrates, de Platão, do Humanismo, do Renascimento, de Kant etc.: aquela dimensão em que todo homem inteligente se exalta no saber-se humano. Portanto é o homem da civilização, da responsabilidade eco ambiental é o homem que sabe trabalhar e também sabe ser protagonista (MENEGHETTI, 2015 , p. 35).

Esse homem inteligente e conexo com o real é quem faz história, produz e administra o poder social, quem faz economia, gera desenvolvimento, riqueza e bem estar social. É esse indivíduo que conduz a humanidade à constante evolução. O Humanismo histórico-civil florentino-italiano permanece, segundo Meneghetti:

O período mais alto que a história tenha vivido para a cultura humanista, encorajava uma atividade social em liberdade e dignidade do homem, ou seja, promovia o desenvolvimento de quatro valores principais: 1) a vida ativa; 2) a socialidade; 3) a liberdade; 4) a dignidade do homem (MENEGHETTI, 2014, p. 56).

Desse modo, podemos dizer que, segundo uma perspectiva humanista (observada através do ponto de vista da Ontopsicologia) é válido o homem que opera ativamente, que faz evolução em conjunto com os outros, que é livre (ou seja, goza da capacidade de ponderar e decidir de forma autônoma) e que realiza a si mesmo, criando e transformando o contexto a sua volta de modo superior e transcendental.

Portanto, experiências de formação que sejam capazes de elevar o homem a essa condição são indispensáveis em todos os níveis da educação.

Com esse contexto em vista, na cidade de Santa Maria ${ }^{9}$ no ano de 2011, demos início a proposta de uma escola de artes marciais para jovens e adultos, focada na formação de um indivíduo que, através do aprendizado do Taekwondo ${ }^{10}$, faz-se responsável a medida que aprende e pratica as técnicas da arte marcial e a luta propriamente dita. A formação na arte marcial pode iniciar em qualquer fase da vida, desde os três anos de idade até a terceira idade, não há época ideal para começar, porém cada faixa etária possui características próprias, e a necessidade de organizá-los em turmas surge quando pretendemos escolher a linguagem que mais se adapta a lição e ao aluno. Portanto, as turmas são divididas dos 03 (três) aos 06 (seis) anos; dos 07 (sete) aos 10 (dez) anos; dos 11 (onze) aos 14 (catorze) anos e; dos 15 (quinze) anos em diante.

\footnotetext{
${ }^{9}$ Santa Maria é uma cidade situada no interior do estado do Rio Grande do Sul no Brasil.

10 Arte marcial coreana cujos primeiros relatos históricos datam de aproximadamente dois mil anos.
} 


\section{Método}

No que se refere ao método, o presente trabalho divide-se em dois: Observação participante e pesquisa bibliográfica. Como se trata não só de uma pesquisa científica, mas primeiramente de um relato de caso, a observação participante consta como método responsável por evidenciar todos os fenômenos de mudança de personalidade, construção de si mesmo, responsabilização, desenvolvimento de autoestima, desenvolvimento das habilidades de liderança e protagonismo. Ao longo dos últimos cinco anos, atuei como observador participante, não só no processo de educação, mas também registrando os progressos dos indivíduos que frequentaram a escola através de interações com seus círculos sociais, famílias, colégios e alguns ambientes de trabalho. Nesse período pude colher relatos acerca das mudanças desenvolvidas pelos indivíduos a partir do ponto de vista de terceiros e deles mesmos.

A segunda etapa deste trabalho consiste em pesquisa bibliográfica acerca da fundamentação teórica (já apresentada) que dá a evidência das categorias teórico-empíricas encontradas nos resultados da observação participante. É interessante observar que, por não se tratar de uma iniciativa com finalidade de pesquisa científica em sua origem, o fenômeno "escola de artes marciais" a ser estudado aqui, desenvolve-se e apresenta resultados de forma natural, sem a influência ou ingerência do cientista que, por vezes, acaba adulterando acidental e inconscientemente, os resultados do próprio experimento.

Para realizar a análise e discussão dos resultados, partiremos do relato de dois casos específicos de desenvolvimento pessoal e após faremos uma análise de conteúdo, através da fundamentação teórica e da discussão dos fenômenos envolvidos no aprendizado da arte marcial.

\section{Resultados e Discussão}

Durante os últimos cinco anos de trabalho, pude testemunhar diversos casos de desenvolvimento da personalidade responsável e protagonista, não só em nível educacional como também terapêutico $^{11}$. Dentre os casos de mais de 300 alunos que já estiveram sob a

\footnotetext{
${ }^{11}$ É importante salientar que, apesar da prática de artes marciais, como relatada neste trabalho, não ser uma forma de terapia, é possível observar alguns efeitos terapêuticos em seus praticantes, como se evidenciará no relato do segundo caso.
} 
nossa tutela, cito dois casos particularmente interessantes em termos de resultados. $\mathrm{O}$ primeiro é o caso de um jovem, que chamaremos de Antônio ${ }^{12}$. Aos 11 anos de idade, Antônio foi trazido à escola por seus pais, esses me disseram que queriam proporcionar a ele uma oportunidade de formação mais completa do aquela que havia à disposição no município onde residia, há 80 quilômetros de Santa Maria-RS. Com o intuito de aprender a arte marcial, os pais de Antônio o traziam duas vezes por semana a Santa Maria para praticar. Quando iniciou, Antônio era uma criança tímida, falava pouco e demonstrava alguns traços de insegurança, mas apresentava um desenvolvimento cognitivo compatível com a sua idade, e não teve dificuldades em aprender os "pilares" da escola; com certa facilidade para aprender a técnica, logo começou a se voluntariar em ocasiões onde o instrutor estimulava os alunos a demonstrar aquilo que haviam compreendido e a ensinar outros que ainda não haviam conseguido fazer aquela passagem no processo de aprendizagem da técnica. Já começava ali a demonstrar ganhos de autoconfiança e, o prestígio que conquistou junto aos seus colegas (ao fazer aquele tirocínio) lhe conferia aos poucos ganhos de autoestima e autoconhecimento. Poucos meses depois, Antônio trouxe à escola um colega de colégio, da cidade onde morava para também praticar.

Um ano depois de haver iniciado, Antônio, com o apoio da família, começou a organizar uma turma de interessados a praticar a arte marcial em seu próprio município, e convidou-me para ir até lá ministrar aulas. Atualmente, agora com 17 anos, muito próximo de conquistar a faixa preta $^{13}$, Antônio é responsável (voluntariamente e por iniciativa própria) por uma turma em seu município, para qual ministro aula uma vez por semana, da qual fazem parte, inclusive, seu pai e sua mãe. E ainda, sob orientação e supervisão, ele próprio ministra outras duas aulas por semana.

Antônio é um jovem responsável e que faz protagonismo dentro do próprio contexto social, é atualmente o presidente do grêmio estudantil de sua escola e já esboça inclinações para a liderança comunitária. Esse caso é um excelente exemplo de como a arte marcial, quando bem ensinada e administrada, pode desenvolver o protagonismo responsável e potencializar a construção de si mesmo do indivíduo. Fica evidente a importância desse resultado quando observamos o que afirma Wazlawick (2014) quando fala sobre pedagogia ontopsicológica na adolescência:

\footnotetext{
12 O nome original foi substituído por Antônio para preservar a identidade do aluno.

${ }^{13}$ No Taekwondo, a faixa preta representa o nível avançado de conhecimento.
} 
No percurso de formação humanista ontopsicológica prática o jovem não pode ser substituído - responsabilidade é o ponto central desta formação. Ele deve assumir a responsabilidade em construir a si mesmo e a própria estrada (WAZLAWICK, 2014, p.41).

O segundo caso é completamente diverso do primeiro. Relatarei o caso de João ${ }^{14}$ um senhor de 49 anos a época, pedreiro, que chegou à escola com o intuito de aprender a "brigar" pois jogava futebol e frequentemente as partidas terminavam de forma violenta. João teve uma origem diferente daquela de Antônio; Nasceu na periferia da Grande Porto Alegre, ${ }^{15}$ teve uma infância marcada por uma família violenta e disfuncional, usou drogas na juventude e viveu uma vida marginalizada até mudar-se e iniciar a profissão que já praticava há 20 anos; porém continuava a viver em um meio social similar aquele da infância.

Quando João iniciou o treinamento, eu lhe disse que não lhe ensinaria a brigar, mas o que lhe ensinaria faria com que a sua vida mudasse bastante. João era o tipo de aluno que havia sido atraído pela escola através da imagem, quis praticar depois de ter assistido uma aula como espectador.

Recordo-me que logo ao aprender sobre os "pilares" da escola, João comentou que se sentia estranho, pois nunca havia sido chamado de "senhor" em um ambiente como aquele $^{16}$. João era um aluno com muita dificuldade de aprender a técnica, tinha suas limitações físicas, tinha pouca autoestima e autoconfiança, em virtude de sua origem. Porém, gradualmente, na medida em que aprendia e que se relacionava com os demais colegas em um ambiente que, através da linguagem, se sentia à vontade e como um igual entre seus pares, João se tornava cada vez menos agressivo em personalidade, e mais alegre, mais extrovertido, mais solícito e mais consciente de si mesmo. Depois de dois anos de treinamento, João me perguntou se poderia conversar em particular, e disse que gostaria de me agradecer por ter cumprido com aquilo que havia dito quando ele iniciou, a arte marcial realmente havia mudado a vida dele. João não jogava mais futebol com aqueles outros violentos com quem se relacionava antes, não brigava nem discutia com os filhos, comprou um pequeno terreno, afastado da periferia onde morava e estava

\footnotetext{
14 O nome original foi substituído por João para preservar a identidade do aluno.

15 "Grande Porto Alegre" é a região metropolitana da cidade capital do estado do Rio Grande do Sul.

${ }^{16}$ É importante salientar que o ambiente desta escola é de um nível socioeconômico relativamente alto, uma vez que a mensalidade custa em média $25 \%$ de um salário mínimo, portanto não era um ambiente ao qual João estava acostumado a frequentar; Note-se que João pagou como qualquer outro, em momento nenhum recebeu qualquer tipo de assistencialismo. Sem dúvida, esse fator foi essencial para que João valorizasse o aprendizado e preservasse sua autoestima, principalmente no começo, quando os resultados físicos são menos aparentes.
} 
construindo a própria casa aos poucos. Segundo as palavras de João, se ele não tivesse conhecido a nossa escola provavelmente jamais teria sido capaz de mudar a própria vida de tal forma.

De todos os casos com os quais me deparei nesse período, considero o caso de João o mais ilustrativo ao argumento de que protagonismo responsável é aquele que permite a construção de si mesmo e a realização pessoal.

De modo a analisar esses dois casos é necessário compreender que a escola, enquanto conceito abstrato funciona por meio de dois "pilares" fundamentais: a disciplina e o respeito.

Dentro da estrutura da arte marcial, a disciplina funciona como regulador das inseguranças presentes em todo iniciante, como se as colocasse em suspensão. Ao começar o treinamento o aluno assume um compromisso tácito e consciente de se esforçar para ser o mais disciplinado possível, isso implica em transpor os sentimentos de inaptidão que surgem quando tenta executar a técnica e falha, levando-o a repetir a tentativa até que acerte e faça a passagem progressiva para a próxima etapa do aprendizado da técnica. $\mathrm{Ou}$ seja a disciplina é indispensável ao tirocínio que leva à excelência do fazer.

Em paralelo, o respeito é um valor que se insere na estrutura formativa do aluno através da linguagem e da imagem. Quando o praticante inicia em nossa escola, a primeira regra que lhe é ensinada é a norma de tratamento: ao se referir à alguém, quem quer que seja, deve-se utilizar os pronomes de tratamento formais; "senhor" para homens de qualquer idade (e isso inclui aqueles com três anos de idade); "senhora" ou "senhorita" para mulheres (de acordo com a aplicação adequada da norma culta da língua). É importante frisar que todos os alunos (sem exceção), pais e familiares, devem, obrigatoriamente, seguir essa regra criando, através da linguagem e postura, um ambiente em que os espaços pessoais e coletivos se tornam bem delineados, mantendo as relações sempre em equilíbrio. A estrutura desse ambiente suspende a disputa por espaço nas relações, equalizando a posição social de todos a despeito das suas diferenças individuais. Ao anular essas diferenças (idade, gênero, poder aquisitivo, etc.) cria-se um ambiente onde todos são iguais e o único caminho para a busca pelo primado é a excelência na busca pela melhor técnica, ou seja, só se destaca aquele que faz, e quando faz, protagoniza.

Esses dois elementos da estrutura (disciplina e respeito) têm o objetivo de criar o ambiente adequado para o desenvolvimento da responsabilidade através do tirocínio da técnica propriamente dita. Responsabilidade é a capacidade de "dar resposta” a algo, 
etimologicamente significa “[...] reação a um estímulo, e que deste depende para realizarse [...]" (HOUAISS, 2009, p. 1653). Quando o aluno aprende uma técnica de ataque ou de defesa em sua totalidade, ele aprende como faz e pra que serve, de modo que esse conhecimento empodera o aluno no sentido em que, ao conhecer a resposta (defesa) ao estímulo (ataque) ou vice-versa, ele se sente capaz de interagir de forma positiva naquela situação, se sente agente capaz de decisão e de ação naquele momento, proporcionando a si mesmo um verdadeiro ganho de autoestima e autoconhecimento. Posteriormente, através da analogia entre os estímulos e reações condicionados com o aprendizado da arte marcial e a capacidade de responder as problemáticas cotidianas, o aluno desenvolve a responsabilidade individual e social, pois o ganho de autoestima e autoconhecimento o acompanham para fora da escola. Assim sendo, gradualmente o aluno passa a buscar a responsabilidade também no contexto em que vive, porque já se sente capaz de "decidir e fazer", por consequência faz e se torna um protagonista em sua própria vida e no contexto social em que atua.

\section{Considerações Finais}

Considerando os relatos de experiência, e a fundamentação teórica apresentada, pudemos evidenciar como um ambiente informal de aprendizado, do ponto de vista acadêmico, é capaz de formar cidadãos capazes de compreender e cumprir seus deveres pessoais e sociais. Através da arte marcial, e do compromisso profissional do instrutor que a ensina, os praticantes são capazes de percorrer uma trajetória de autoconhecimento através do tirocínio da técnica, tornando-se responsáveis por si mesmos e pelos ambientes sociais em que vivem. Uma formação protagonista é capaz não só de fazer economia social, mas também de resgatar as possibilidades do indivíduo de ser positivo para si mesmo e para os outros.

Ao analisar este estudo e relato de experiência, é possível destacar claramente o papel da responsabilização do indivíduo na passagem para o autofundar-se em si mesmo como categoria teórico-empírica de forte evidência, uma vez que a relação de causa e efeito entre essa passagem e a adoção de uma postura protagonista se faz sempre presente. No entanto este trabalho não encerra o tema como objeto de pesquisa para futuros estudos, pois o embasamento teórico trazido como argumento abre um extenso leque de possibilidades para pesquisas teóricas e de campo, com diversas outras faixas etárias, 
condições sociais, origens culturais, direcionamento de pesquisa e tantas variáveis quantas o pesquisador possa inserir no mesmo contexto.

A sociedade em que vivemos, e que contemporaneamente colaboramos para construir, "suplica" por uma nova abordagem na formação da juventude. Não apenas pelas evidências das falhas nos resultados da pedagogia sistêmica atual, mas principalmente porque a nossa perpetuação enquanto sociedade depende diretamente de uma pedagogia que reconecte o jovem com a verdade de si mesmo, uma pedagogia verdadeira, real, ôntica.

Nós jovens somos os que detêm o potencial para perpetuar a humanidade de forma superior, ou condená-la a própria extinção. Para perpetuá-la é preciso que empreendamos a própria formação dentro da lógica do dever e da responsabilidade do fazer sempre em maior capacidade de protagonismo.

\section{Referências}

HOUAISS, A. Dicionário Houaiss da Língua Portuguesa. Rio de Janeiro: Objetiva, 2009.

MENEGHETTI, A. Manual de Ontopsicologia. 4. ed. Recanto Maestro: Ontopsicológica, 2010.

MENEGHETTI, A. Dicionário de Ontopsicologia. 2. ed. Recanto Maestro: Ontopsicológica Editora Universitária, 2012.

CAROTEnUtO, M. A Paideia Ôntica: Dos Sumérios a Meneghetti. Recanto Maestro: Ontopsicológica Editora Universitária, 2013.

MENEGHETTI, A. Do Humanismo Histórico ao Humanismo Perene. Recanto Maestro: Ontopsicológica Editora Universitária, 2014.

MENEGHETTI, A. Arte, Sonho e Sociedade. Recanto Maestro: Ontopsicológica Editora Universitária, 2015.

WAZLAWICK, P. Princípios Práticos de Uma Pedagogia Para o Adolescente. In: Fundação Antonio Meneghetti. Uma Nova Pedagogia Para a Sociedade Futura: Princípios Práticos. Recanto Maestro: Ontopsicológica Editora Universitária, 2015. 